\title{
A enunciação escrita em Benveniste: notas para uma precisão conceitual ${ }^{*}$ \\ The written enunciation in Benveniste: notes for a conceptual framework
}

Valdir do Nascimento FLOREs*

(Universidade Federal do Rio Grande do Sul - Instituto de Letras/ Departamento de Letras Clássicas e Vernáculas - Porto Alegre - RS - Brasil)

\section{RESUMO}

Este texto apresenta uma proposta de interpretação para a expressão enunciação escrita, presente em "O aparelho formal da enunciação", de Émile Benveniste, com vistas ao estabelecimento de princípios norteadores do estudo da enunciação escrita no quadro formal de realização da enunciação. Procede-se a um estudo de natureza conceitual para, em seguida, apresentar, em termos prospectivos, possibilidades de abordagem. Para tanto, procede-se a um estudo conceitual não apenas no referido artigo, mas também em outros textos do autor em que o tema da escrita é abordado para, finalmente, precisar-se o sentido que se pode atribuir à

\footnotetext{
* Este texto retoma, parcialmente e com modificações, a terceira aula do Curso ministrado junto ao Institut des Textes et Manuscrits Modernes (ITEM), no Séminaire Génétique et théories linguistiques du cadre du Labex TransferS «Genèse et transferts de savoirs linguistiques », da École Normale Supérieure - Paris, ocorrido entre janeiro e fevereiro de 2016, a propósito da recepção de Ferdinand de Saussure e Émile Benveniste no Brasil. ** Professor Titular em Língua Portuguesa do Departamento de Letras Clássicas e Vernáculas e do Programa de Pós-graduação em Letras da UFRGS. Pesquisador do CNPq.
} 
expressão. O resultado da pesquisa indica que há diferenças de tratamento do problema da escrita na obra do autor, permitindo concluir que a expressão enunciação escrita, apesar de guardar relações com a noção geral de escrita, se distingue desta em função de sua vinculação ao quadro formal de realização da enunciação esboçado por Benveniste.

Palavras-chave: Enunciação escrita; enunciação; escrita; discurso.

\begin{abstract}
This article presents a proposal to interpret the expression written enunciation, present in "The formal apparatus of enunciation", by Émile Benveniste, aiming to establish guiding principles to study the written enunciation within the formal framework of the event of enunciation. A study with conceptual nature is carried out and possible approaches are subsequently presented, in prospective terms. In order to do so, a conceptual study considering not only the aforementioned article but also other texts in which the subject of writing is addressed by the author is conducted, so as to finally define the meaning that may be assigned to the expression. The result of the research indicates that there are differences in the treatment of the problem of writing in the author's work, allowing the conclusion that, despite bearing relations with the general notion of writing, the expression written enunciation differs from it due to its connection to the formal framework of realization of the enunciation outlined by Benveniste.
\end{abstract}

Key-words: Written enunciation; enunciation; writing; discourse.

\title{
1. Introdução
}

O objetivo deste texto é dar início a um estudo crítico-conceitual que permita derivar uma concepção de escrita - na verdade, como será visto, de enunciação escrita - no quadro da reflexão enunciativa oriunda do linguista Émile Benveniste ${ }^{1}$.

1. Há, no Brasil, alguns trabalhos que têm buscado contemplar aspectos desse mesmo objetivo. Vale citar os trabalhos de Silva (2016a e 2016b), Knack (2012), Toldo; Flores (2015), Mello; Schwabe; Stein (2015), entre outros. No entanto, optei por fazer um caminho particular, neste momento, menos por alguma divergência com as abordagens 
A tarefa, em um primeiro momento, parece ser fácil, pois, como se sabe, em Dernières leçons: Collège de France 1968-1969, livro organizado por Jean-Claude Coquet e Irène Fenoglio e recentemente publicado $^{2}$ no Brasil, Benveniste se dedica a refletir sobre a escrita. Assim, aparentemente, bastaria entender o percurso feito por Benveniste em suas Últimas aulas para obter-se uma proposta benvenistiana de estudo da escrita.

No entanto, não é assim que penso. Na verdade, creio que deslocar as ideias de Benveniste para abordar a escrita, em sua realidade enunciativa, continua a ser um desafio muito difícil de ser superado, e a reflexão presente nas Últimas aulas não parece ser, em um primeiro momento, a solução para o problema. E eu tenho dois motivos para acreditar que as Últimas aulas não são, em si, suficientes para subsidiar uma abordagem enunciativa da escrita.

O primeiro motivo é que, como tenho procurado demonstrar (cf. Flores 2013a e 2013b), há grande flutuação terminológica nos textos de Benveniste.

É fácil encontrar, em seus artigos, termos que, apesar de idênticos do ponto de vista da expressão, são completamente distintos quanto ao significado (uso homonímico). Há também termos que são diferentes do ponto de vista da expressão, mas relativos ao mesmo conceito (uso sinonímico). Há, ainda, termos que adquirem nuances de sentido em diferentes momentos de reflexão do autor (uso polissêmico). Tais relações semântico-terminológicas podem ser encontradas comparando-se alguns textos entre si e mesmo dentro de um único texto.

Tome-se, a título de exemplo, a flutuação conceitual do termo sentido no texto "Os níveis de análise linguística". Nesse artigo, há mais de trinta ocorrências de sentido.

Uma dessas ocorrências aparece em uma definição do tipo $X e ́ Y$, o que é muito raro em Benveniste. Diz ele: "O sentido de uma unidade

listadas e mais pela intenção de sistematizar uma leitura própria da questão da escrita em Benveniste.

2. O livro foi publicado em 2012, na França, e traduzido, em 2014, no Brasil, sob a minha direção, com o título Últimas aulas no Collège de France 1968-1969 (cf. Referências Bibliográficas). Usaremos aqui ambas as edições, de acordo com a necessidade. 
linguística define-se como a sua capacidade de integrar uma unidade de nível superior" (Benveniste 1988: 136, grifo meu). E exemplifica:

Na língua organizada em signos, o sentido de uma unidade é o fato de que ela tem um sentido, de que é significante. O que equivale a identificá-la pela sua capacidade de exercer uma "função proposicional". Essa é a condição necessária e suficiente para que reconheçamos essa unidade como significante. Numa análise mais exigente, teríamos de enumerar as "funções" que essa unidade está apta a exercer, e - em suma - deveríamos citá-las todas. Semelhante inventário seria bastante limitado para méson, ou crisópraso, imenso para coisa ou um; pouco importa; obedeceria sempre ao mesmo princípio de identificação pela capacidade de integração. Em todos os casos estaríamos em posição de dizer se determinado segmento da língua "tem um sentido" ou não (Benveniste 1988: 136, grifo meu).

Mas é o próprio Benveniste quem adverte logo a seguir: "A noção de sentido, porém, tem ainda um outro aspecto" (Benveniste 1988: 136). E acrescenta: "Um problema totalmente diferente consistiria em perguntar: qual é esse sentido? Aqui 'sentido' se toma numa acepção completamente diferente" (Benveniste 1988: 136, grifo meu). Grosso modo, então, Benveniste estabelece aqui, no mínimo, dois "sentidos" para sentido ${ }^{3}$ :

a) o que decorre da capacidade de integração de um elemento, "inerente ao sistema linguístico e às suas partes" (Benveniste 1988: 137);

b) o que está contido na pergunta "qual é esse sentido?", que nada mais é que o referendum que decorre de "situações concretas e específicas” (Benveniste 1988: 137).

Do ponto de vista terminológico, entre esses dois usos de sentido - como integração e como referendum - não há mais que uma relação de homonímia: mesma expressão para conceitos distintos.

Ainda um último exemplo dentro desse mesmo texto: o uso do termo frase, nas três ocorrências abaixo:

3. Na verdade, há outros sentidos para o termo. No entanto, como ilustração, basta o exemplo fornecido acima. 
1) "Uma frase não pode, pois, servir de integrante a outro tipo de unidade. Isso se prende antes de tudo ao caráter distintivo entre todos, inerente à frase, de ser um predicado" (Benveniste 1988: 137, grifo meu);

2) "A frase, criação indefinida, variedade sem limite, é a própria vida da linguagem em ação. Concluímos que se deixa com a frase o domínio da língua como sistema de signos e se entra num outro universo, o da língua como instrumento de comunicação, cuja expressão é o discurso" (Benveniste 1988: 139, grifos meus);

3) "A frase é uma unidade, na medida em que é um segmento de discurso". (Benveniste 1988: 139, grifo meu).

Não é possível deixar de observar que, na primeira passagem, há uma visão formal de frase, compatível com aspectos sintáticos; na segunda, entretanto, frase é termo que permite entrar num outro universo, o da linguagem em ação; na terceira, enfim, frase é vista como um segmento de discurso. Há, portanto, a exemplo do que ocorreu com o termo sentido acima, uma homonímia.

Levando em consideração essa flutuação terminológica em Benveniste, quero colocar em discussão um ponto relativo ao termo escrita.

Como se sabe, Benveniste não fala em escrita apenas nas Últimas aulas. É verdade que, nelas, o tema tem grande destaque. Eu diria mesmo que é o grande assunto. No entanto, não se pode ignorar que Benveniste tratou o tema, mesmo que rapidamente, em seus outros estudos. Assim, vale perguntar: a escrita que está presente nos demais trabalhos de Benveniste é a mesma que está presente em Últimas aulas no Collège de France 1968 e 1969 (Benveniste, 2014)? Há diferenças? Há semelhanças? Haveria a possibilidade de o uso do termo escrita nas Últimas aulas, e também em alguns outros textos de Benveniste, ser apenas um caso de homonímia do mesmo tipo dos usos homonímicos de sentido ou de frase ilustrados acima?

O segundo motivo que tenho para pensar que as Últimas aulas não são, em si, a solução para a abordagem enunciativa da escrita é que não parece que o que Benveniste chama de escrita nas Últimas aulas seja, pari passu, compatível com os propósitos enunciativos apresentados pelo autor em textos consagrados à problemática da enunciação como, 
por exemplo, no artigo "O aparelho formal da enunciação". Logo, isso caberia ser melhor investigado.

A partir dessas considerações introdutórias, este texto apresenta-se, então, dividido em três partes. A primeira busca responder à seguinte pergunta: como a escrita comparece nos demais trabalhos de Benveniste que não nas Últimas aulas? Sobre isso, darei alguns exemplos, em geral, e apenas um exemplo aprofundadamente: a presença da escrita no texto "O aparelho formal da enunciação". A segunda parte buscará responder à seguinte pergunta: que escrita está presente nas Últimas aulas? Nessa parte, meu objetivo é minimizar o efeito de ambiguidade que a flutuação terminológica de Benveniste pode provocar. Finalmente, na terceira parte, já de posse da desambiguização terminológica, pretendo sugerir alguns princípios que poderiam nortear uma abordagem da enunciação escrita. Finalmente, são apresentadas as conclusões.

\section{Da escrita à enunciação escrita em Benveniste}

O conjunto de trabalhos de Benveniste publicados em Problemas de linguística geral já é suficiente para se ter uma ideia dos usos que o termo escrita tem para o autor. Cabe destacar alguns:

a) Uso ligado à ideia de sistemas de representação (alfabético, silábico etc.), o que o permite falar em "tipos" de escrita: "A escrita alfabética difere assim no seu princípio da escrita chinesa que é morfemática ou da escrita cuneiforme que é silábica" (Benveniste 1988: 25);

b) Uso ligado à noção de língua escrita, o que o permite falar em marcas da "língua escrita" em contraste com a "língua falada":

Há um ponto no qual o sistema [verbal do francês moderno] se faz indevidamente redundante: é a expressão temporal do "passado", que dispõe de duas formas, il fit e il a fait [ = "ele fez"]. Na interpretação tradicional, seriam duas variantes da mesma forma, entre as quais se escolhe, segundo se escreva (il fit) ou se fale (il a fait). Teríamos aqui o indício de uma fase de transição na qual a forma antiga (il fit) se mantém na língua escrita, mais conservadora, enquanto a língua falada indica de antemão, instalada, a forma de substituto (il a fait) concorrente e destinada a impor-se sozinha (Benveniste 1988: 261, grifos meus). 
c) Uso ligado à concepção de sistema semiótico ${ }^{4}$ :

É necessário aqui precisar a natureza e as possibilidades das relações entre sistemas semióticos. (...).

$1{ }^{\circ}$ Um sistema pode engendrar um outro sistema. A língua usual engendra a. formalização lógico-matemática; a escrita ordinária engendra a escrita estenográfica; o alfabeto normal engendra o alfabeto Braile. Esta RELAÇÃO DE ENGENDRAMENTO vale entre dois sistemas distintos e contemporâneos, mas de mesma natureza, sendo que o segundo é construído a partir do primeiro e preenche uma função específica. E necessário distinguir cuidadosamente esta relação de engendramento da relação de derivação, que supõe evolução e transição histórica. Entre a escrita hieroglífica e a escrita demótica há derivação, não engendramento. A história dos sistemas de escrita fornece um grande número de exemplos de derivação (Benveniste 1989: 61, grifos meus).

Esses exemplos ilustram que a flutuação terminológica benvenistiana, lembrada na Introdução, se estende à escrita, a exemplo do que acontece com outros termos utilizados pelo autor.

De todos os usos do termo, há um que, em minha opinião, chama muito a atenção e, por isso, não o incluí na lista das ocorrências acima, já que ele merece maior reflexão. Trata-se do uso no artigo "O aparelho formal de enunciação", de 1970.

No final de "O aparelho", encontra-se a seguinte passagem:

Muitos outros desdobramentos deveriam ser estudados no contexto da enunciação. Ter-se-ia que considerar as alterações lexicais que a enunciação determina, a fraseologia, que é a marca frequente, talvez necessária, da "oralidade". Seria preciso também distinguir a enunciação falada da enunciação escrita. Esta se situa em dois planos: o que escreve se enuncia ao escrever e, no interior de sua escrita, ele faz os indivíduos se enunciarem. Amplas perspectivas se abrem para a análise das formas complexas do discurso, a partir do quadro formal esboçado aqui (Benveniste 1989: 90, grifo meu).

4. Esse uso do termo escrita será de extrema importância para a reflexão desenvolvida no âmbito das Últimas aulas. Voltarei a isso adiante. 
O que convida à reflexão aqui é a expressão enunciação escrita. Em "O aparelho", Benveniste se esforça para apresentar uma espécie de síntese de seu pensamento acerca da enunciação, entendida como um fenômeno geral. No entanto, na passagem acima, ele utiliza o termo enunciação com sentido bem específico. Haveria, conforme indica a citação, uma enunciação falada e uma enunciação escrita. Trata-se, agora, de tipos de enunciação, não mais de sistemas de representação ou mesmo de sistemas semióticos.

Para elaborar algumas conclusões relativas ao emprego dessa expressão, nesse artigo, é importante, antes, acompanhar em detalhe o raciocínio de Benveniste.

"O aparelho" provocou grande impacto na linguística de seu tempo - e mesmo na mais recente - em função da formulação explícita de uma definição de enunciação. Poucas vezes Benveniste é tão claro na elaboração de um conceito. Diz ele: "A enunciação é este colocar em funcionamento a língua por um ato individual de utilização" (Benveniste 1989: 82). E acrescenta, logo adiante: "Este grande processo [a enunciação] pode ser estudado sob diversos aspectos" (Benveniste 1989: 82).

Em "O aparelho", Benveniste limita-se a abordar um aspecto desse grande processo, qual seja, o quadro formal de realização da enunciação: "Tentaremos esboçar, no interior da língua, os caracteres formais da enunciação a partir da manifestação individual que ela atualiza" (Benveniste 1989: 83, grifos meus).

Para fazer esse esboço, Benveniste propõe um verdadeiro caminho metodológico. Segundo ele, para estudar o quadro formal de realização da enunciação, é necessário fazer um percurso (é esse o sentido que dou ao grifo a seguir): "Na enunciação consideraremos, sucessivamente, o próprio ato, as situações em que ele se realiza, os instrumentos de sua realização" (Benveniste 1989: 83, grifo meu).

Em outras palavras, o linguista, para proceder à análise enunciativa, deve, seguindo o percurso acima, partir do ato, examinar a situação em que se dá esse ato e, finalmente, descrever os instrumentos (os recursos linguísticos) que tornaram possível o ato. 
E o que é o ato? É Benveniste mesmo quem esclarece: "O ato individual pelo qual se utiliza a língua introduz em primeiro lugar o locutor como parâmetro nas condições necessárias da enunciação" (Benveniste 1989: 83). Esse ato supõe diálogo:

[...] desde que ele se declara locutor e assume a língua, ele implanta o outro diante de si, qualquer que seja o grau de presença que ele atribua a este outro. Toda enunciação é, explícita ou implicitamente, uma alocução, ela postula um alocutário (Benveniste 1989: 84, itálico no original).

E o que é a situação? Como Benveniste a define? Na verdade, Benveniste não chega a definir textualmente o conceito de situação, na qual o ato de enunciação se realiza. Ele se limita a dizer que "antes da enunciação, a língua não é senão possibilidade de língua. Depois da enunciação, a língua é efetuada em uma instância de discurso [...]" (Benveniste 1989: 84, grifo meu). É por isso que a "presença do locutor em sua enunciação faz com que cada instância de discurso constitua um centro de referência interno" (Benveniste 1989: 84, grifo meu). A situação, então, é constituída pela instância de discurso, ou seja, pelo conjunto das circunstâncias que inclui as coordenadas de tempo, espaço e pessoa. Além disso, acrescenta Benveniste:

(...) na enunciação, a língua se acha empregada para a expressão de uma certa relação com o mundo. A condição mesma dessa mobilização e dessa apropriação da língua é, para o locutor, a necessidade de referir pelo discurso, e, para o outro, a possibilidade de co-referir identicamente, no consenso pragmático que faz de cada locutor um co-locutor. A referência é parte integrante da enunciação (...) (Benveniste 1989: 84).

Quer dizer: o locutor e o alocutário que, como visto, integram o ato de enunciação, referem e correferem pelo discurso na construção de um sentido singular acerca do que falam. A situação é, nesse sentido, constituída pela instância de discurso na qual locutor e alocutário referem e correferem.

E os instrumentos de realização da enunciação? Sobre isso, afirma Benveniste: 


\begin{abstract}
Enquanto realização individual, a enunciação pode se definir, em relação à língua, como um processo de apropriação. O locutor se apropria do aparelho formal da língua e enuncia sua posição de locutor por meio de índices específicos, de um lado, e por meio de procedimentos acessórios, de outro (Benveniste 1989: 84).
\end{abstract}

Também deve-se precisar bem o que Benveniste quer dizer para se compreender o que o autor está apresentando.

Primeiro ponto: Benveniste utiliza a expressão aparelho formal da língua e não aparelho formal da enunciação. Aliás, não há nenhuma ocorrência da expressão aparelho formal da enunciação no texto, exceção feita ao título, obviamente. No texto, encontra-se apenas a expressão próxima "aparelho linguístico da enunciação" (Benveniste 1989: 88). Em minha opinião, Benveniste quer mesmo chamar a atenção para o fato de o locutor se apropriar da língua, do aparelho formal da língua, e construir com ela um aparelho de enunciação. Isto é, o locutor constrói um aparelho formal de enunciação a cada vez que enuncia, com base no aparelho formal da língua.

E como o locutor faz isso? Como ele enuncia sua posição de locutor? Benveniste responde: por meio de índices especificos, de um lado, e por meio de procedimentos acessórios, de outro. Logo, o dito aparelho formal de enunciação não é algo que está pronto aprioristicamente e que caberia ao locutor acessar, tomar posse, mas é algo construído a cada enunciação a partir dos recursos da língua em uma dada situação.

Segundo ponto: há índices especificos e procedimentos acessórios que permitem ao locutor enunciar sua posição de locutor.

Os índices específicos são o que Benveniste chamou de "caracteres necessários e permanentes" (Benveniste 1989: 83) da enunciação: os índices de pessoa (eu-tu), os índices de ostensão de espaço (este, aqui) e as formas temporais (do presente da enunciação).

É Benveniste quem permite essa interpretação que faço, quando acrescenta, em uma nota de rodapé, ligada à expressão "aparelho necessário" (Benveniste 1989: 85), a afirmação de que "os detalhes dos fatos de língua que apresentamos aqui de um modo sintético estão expostos 
em muitos capítulos de nossos Problemas de linguística geral I' (Benveniste 1989: 85, n. 2). Nesses capítulos, encontram-se seus estudos sobre as categorias de pessoa, de tempo e, muito mais resumidamente, de espaço. A expressão "aparelho necessário", à qual se liga a nota de rodapé, é fundamental, pois ela autoriza a interpretação que faço de que são formas específicas, necessárias, da enunciação apenas as categorias de pessoa, espaço e tempo. Os demais mecanismos são, todos, procedimentos acessórios da enunciação, portanto, não específicos.

Os índices especificos são "[...] primeiramente a emergência dos índices de pessoa (a relação eu-tu)" (Benveniste 1989: 84); "da mesma natureza e se relacionando à mesma estrutura da enunciação [...] os numerosos índices de ostensão (tipo este, aqui, etc.)" (Benveniste 1989: 84-85); "uma terceira série de termos que dizem respeito à enunciação é constituído pelo paradigma [...] das formas temporais, que se determinam em relação a $E G O$, centro da enunciação" (Benveniste 1989: 85). Ou seja, “os 'tempos' verbais cuja forma axial, o 'presente', coincide com o momento da enunciação, fazem parte deste aparelho necessário" (Benveniste 1989: 85, grifo meu).

Os procedimentos acessórios, segundo penso, estão ligados à singularidade que cada enunciação evoca, portanto, à língua toda. Assim, além dos índices específicos, a enunciação se vale de procedimentos acessórios. Benveniste lista a intimação, a asserção, a interrogação e as modalidades formais pertencentes aos verbos ou às fraseologias. Enfim, apesar de dar poucos exemplos dos procedimentos acessórios, o raciocínio de Benveniste leva a crer que haveria muitos mecanismos que poderiam ser tomados como acessórios da enunciação ${ }^{5}$.

5. Aresi (2011) apresenta, a esse propósito, uma hipótese que é diferente da minha neste texto, mas que, sem dúvida, valeria ser explorada. Diz o autor: "Quais são os procedimentos acessórios da enunciação? Haveria a possibilidade de listá-los exaustivamente? Evidentemente que não, já que, como diz Benveniste em Os Níveis da Análise Linguística (1964): 'Um inventário dos empregos de uma palavra poderia não acabar; um inventário dos empregos de uma frase não poderia nem mesmo começar' (Benveniste, 1964/2005: 139). Porém, creio que é possível responder, ao invés de "quais", "o que" são os procedimentos acessórios da enunciação, tendo em mente a seguinte passagem de $A$ Forma e o Sentido na Linguagem (1966): '[...] indo além das palavras, a ideia deve sofrer a restrição de leis de seu agenciamento' (Benveniste, 1966/2006: 232, grifo meu). É assim que entendo esse conceito: como processo de agenciamento das formas" (Aresi 2011: 272). 
Em resumo, o quadro formal da enunciação é constituído:

a) pelo ato no qual estão implicados locutor e alocutário;

b) pela situação cuja instância de discurso constitui a referência construída na enunciação;

c) pelos instrumentos de realização (específicos e acessórios).

Com a apresentação do raciocínio de Benveniste em "O aparelho formal da enunciação", estão reunidas as condições para voltar à passagem em que ele preconiza a diferença entre enunciação escrita e enunciação falada. Vou recolocar a passagem:

Seria preciso também distinguir a enunciação falada da enunciação escrita. Esta se situa em dois planos: o que escreve se enuncia ao escrever e, no interior de sua escrita, ele faz os indivíduos se enunciarem. Amplas perspectivas se abrem para a análise das formas complexas do discurso, a partir do quadro formal esboçado aqui (Benveniste 1989: 90, grifo meu).

Levando em conta tudo o que foi visto a respeito da enunciação em "O aparelho", cabe perguntar: qual a especificidade que distinguiria a enunciação escrita? Como essa especificidade poderia ser tomada no quadro formal esboçado por Benveniste? Ou ainda: como se configuraria o aparelho formal da enunciação da enunciação escrita?

Para sintetizar esta parte, gostaria de listar algumas consequências que, segundo penso, deveriam ser consideradas caso se admita o percurso de leitura sugerido até aqui:

a) no contexto teórico de Benveniste, a expressão enunciação escrita não é sinônima da expressão escrita (seja no sentido de escrita alfabética, seja no sentido de língua escrita, seja no sentido de sistema de escrita);

b) apenas a noção de enunciação escrita pode subsidiar uma discussão linguística voltada à abordagem enunciativa da escrita.

Finalmente, uma questão de extrema importância: admitida a interpretação feita até aqui, na teoria de Benveniste não há espaço para expressões como "texto escrito" ou mesmo "enunciado escrito". O termo condizente - cujo valor teórico resta ainda estabelecer - é enun- 
ciação escrita. Assim, excluem-se abordagens textuais de tratamento da escrita. Quanto a isso, é Benveniste mesmo quem adverte: "É preciso ter cuidado com a condição específica da enunciação: é o ato mesmo de produzir um enunciado, e não o texto do enunciado, que é nosso objeto" (Benveniste 1989: 82). Em outras palavras, é o ato de produção da escrita, a enunciação escrita, que interessa a uma abordagem com base em Benveniste, e não o produto desse ato, o enunciado, ou ainda, o texto do enunciado.

\section{A escrita nas Últimas aulas}

O que primeiro chama a atenção, quando se estuda as Últimas Aulas de Benveniste, é o contexto em que a discussão sobre a escrita aparece. Ele é muito diferente do contexto em que a expressão enunciação escrita aparece em "O aparelho formal da enunciação".

E qual é a diferença? Benveniste, em suas Últimas aulas, quer responder questões que advêm do raciocínio saussuriano, embora não tenham sido diretamente colocadas pelo mestre genebrino. Diz Benveniste na quarta aula, de 6 de janeiro de 1969:

\footnotetext{
Nós nos encaminhamos assim para um novo problema. Como é possível que haja sistemas semiológicos? Quantos eles são? Seriam sempre os mesmos sistemas ou sistemas diferentes? E se eles são diferentes, no que se diferenciam? Haveria uma relação entre eles, e se há, qual seria essa relação? Saussure não formulou nenhuma dessas questões. Ele se contentou em remeter à semiologia futura a tarefa de definir o signo, seu lugar, etc. Ele somente disse que a língua era o "principal" sistema semiológico. Porém, sob qual ponto de vista? Seria porque a língua tem o privilégio da universalidade? (Benveniste 2014: 71, grifo meu).
}

Observe-se que a intenção de Benveniste é situar-se na discussão aberta por Saussure relativamente à "Semiologia" e ao lugar da língua frente os demais sistemas semiológicos. Ou seja, Benveniste quer saber por que Saussure considerou a língua um sistema semiológico "principal" em relação aos demais sistemas.

As Últimas aulas estão sob forte influência da distinção semiótico/semântico e ligadas às reflexões do artigo "Semiologia da língua", 
publicado por Benveniste também em 1969. Benveniste, nessas notas, faz um percurso que parte de Ferdinand de Saussure e Charles Sanders Peirce (lições 1, 2 e 3), mantendo-se perto do primeiro e distante do segundo, para "ir além" de Saussure (lição 4) com a proposta de que a língua é o único sistema significante não só capaz de interpretar os outros sistemas como também passível de interpretar a si própria. A língua é o sistema interpretante por excelência (lições 5, 6 e 7).

Nesse sentido, toda a discussão feita em torno da noção de escrita, que se estende por nove aulas ${ }^{6}$, deve estar referida a esse contexto epistemológico.

Na lição 5, de 13 de janeiro de 1969, lê-se:

É preciso agora introduzir, na análise descritiva e comparativa dos sistemas semiológicos, uma nova relação, que Saussure não mencionou, nem talvez tenha visto: a relação de interpretação. Trata-se de determinar se o sistema semiológico considerado pode se interpretar por si mesmo ou se ele deve receber sua interpretação de outro sistema semiológico. A questão que eu coloco é a da relação de interpretação entre sistemas (totalmente diferente da noção de interpretante em Pierce) (Benveniste 2014: 109).

Para Benveniste, a língua é o único sistema que pode ser interpretante de todos os outros sistemas, inclusive de si mesma. Isso está bem claro no artigo "Semiologia da língua", quando Benveniste afirma que "[...] a língua pode, em princípio, tudo categorizar e interpretar, inclusive ela mesma" (Benveniste 1989: 62). Para ele, "a língua nos fornece o único modelo de um sistema que seja semiótico simultaneamente na sua estrutura e no seu funcionamento" (Benveniste 1989: 63). E por quê?

Porque a língua é a grande organização semiótica que há:

1. ${ }^{\circ}$ ela se manifesta pela enunciação, que contém referência a uma situação dada; falar, é sempre falar-de:

2. ${ }^{\circ}$ ela consiste formalmente de unidades distintas, sendo que cada uma é um signo; 
3. ela é produzida e recebida nos mesmos valores de referência por todos os membros de uma comunidade;

4. ${ }^{\circ}$ ela é a única atualização da comunicação intersubjetiva (Benveniste 1989: 63).

Além disso, a língua é o único sistema semiológico que tem a dupla significância do modo semiótico e do modo semântico. E sintetiza:

A língua é o único sistema em que a significação se articula assim em duas dimensões. Os outros sistemas têm uma significância unidimensional: ou semiótica (gestos de cortesia; mudrãs), sem semântica; ou semântica (expressões artísticas), sem semiótica. O privilégio da língua é de comportar simultaneamente a significância dos signos e a significância da enunciação. Daí provém seu poder maior, o de criar um segundo nível de enunciação, em que se torna possível sustentar propósitos significantes sobre a significância. É nesta faculdade metalinguística que encontramos a origem da relação de interpretância pela qual a língua engloba os outros sistemas (Benveniste 1989: 66, grifos meus).

Eu gostaria de chamar a atenção para dois pontos. Benveniste diz que:

a) a língua "pode, em princípio, tudo categorizar e interpretar" (Benveniste 1989: 62);

b) a língua "pode [...] interpretar, inclusive ela mesma" (Benveniste 1989: 62).

Se li bem o artigo "Semiologia da língua" e as Últimas aulas, Benveniste não chega a dar maiores informações de como a língua "engloba os outros sistemas". No máximo, pode-se dizer que ele formula o princípio.

Nas Últimas aulas, porém, ele mostra como a língua interpreta a si própria, o que ele chama de "autossemiotização da língua" (Benveniste 2014: 155). A escrita seria, então, a prova de que a língua interpreta a si própria. A escrita é a evidência da autossemiotização da língua. Esse é o contexto em que a escrita aparece nas Últimas aulas.

$\mathrm{Na}$ aula 12, de 3 de março de 1969, isso fica bem mais claro. Leia-se: 
A autossemiotização da língua:

A escrita foi sempre e por toda parte o instrumento que permitiu à língua semiotizar a si mesma.

Isso quer dizer que o falante de detém sobre a língua em vez de se deter sobre as coisas enunciadas; ele leva em consideração a língua e a descobre significante; ele observa recorrências, identidades, diferenças parciais, e essas observações se fixam em representações gráficas que objetivam a língua e que suscitam, enquanto imagens, a própria materialidade da língua.

A escrita e, mais particularmente a escrita alfabética, é o instrumento da autossemiotização da língua. Como? Em virtude das seguintes proposições: 1) A língua é o único sistema significante que pode descrever a si mesmo em seus próprios termos. A propriedade metalinguística é própria à língua, pelo fato de ela ser o interpretante dos outros sistemas.

2) Mas para que a língua se semiotize, deve proceder a uma objetivação de sua própria substância. A escrita torna-se progressivamente o instrumento dessa objetivação formal (Benveniste 2014: 155-156).

Em resumo, as Últimas aulas são um momento de evidente desenvolvimento de um aspecto do mecanismo de interpretância da língua, anunciado no texto "Semiologia da língua", o da interpretância da língua por ela mesma. Portanto, a escrita é chamada a comparecer ali em função de suas características semiológicas e não como enunciação escrita. Em outras palavras, o termo escrita em Últimas aulas não é sinônimo da expressão enunciação escrita, presente em "O aparelho formal da enunciação". Mais uma vez, trata-se apenas de uma homonímia em Benveniste, o que significa que a noção de enunciação escrita não é, no contexto da teoria de Benveniste, equivalente à noção de escrita que está presente nas Últimas aulas.

\section{A escrita na enunciação}

No início deste texto, disse que minha intenção é dar início a um estudo que permita derivar uma concepção enunciativa de escrita, no quadro da reflexão enunciativa oriunda do linguista Émile Benveniste. E como penso que é possível fazer isso? 
Inicialmente, é preciso considerar o caráter prospectivo de um trabalho dessa natureza. Quer dizer: Benveniste não desenvolveu essa reflexão, portanto, configura-se um projeto de pesquisa o desenvolvimento desse ponto de sua teoria. Vou aqui, portanto, apenas formular algumas ideias iniciais.

Vale lembrar que o quadro formal de realização da enunciação escrita, quando se toma por base o que está formulado em "O aparelho formal da enunciação", deveria ser constituído pelo próprio ato, pela situação em que o ato se realiza e pelos instrumentos de realização.

Em termos de prospecção de uma pesquisa que vise ao desenvolvimento de uma concepção de escrita no quadro da teoria enunciativa, cabe, então, recolocar cada um desses elementos e as questões de pesquisa que implicam.

\subsection{O ato da enunciação escrita}

Considere-se, então, o que diz "O aparelho" a respeito do ato de enunciação em geral e as respectivas indagações que prospectam uma pesquisa acerca da enunciação escrita. Vou recolocar a formulação de Benveniste a respeito do ato de enunciação. Diz o autor: "O ato individual pelo qual se utiliza a língua introduz em primeiro lugar o locutor como parâmetro nas condições necessárias da enunciação" (Benveniste 1989: 83, grifo meu).

A partir disso, cabe perguntar: quem é o locutor parâmetro das condições necessárias da enunciação escrita? O autor do texto? Para responder a essas perguntas, seria necessário compreender em detalhe três pontos sintetizados, acima, nas expressões "introduz", "parâmetro" e "condições necessárias", destacadas na citação.

O ato de enunciação "introduz" o locutor como "parâmetro", ou seja, como uma espécie de variável a partir da qual se pode atribuir valor às demais variáveis que constituem a enunciação. Logo, "as condições necessárias da enunciação" assim o são a partir do "parâmetro" locutor. Isso é reiterado logo adiante em "O aparelho", quando Benveniste diz que " $\mathrm{O}$ ato individual de apropriação da língua introduz aquele que fala em sua fala" (Benveniste 1989: 84, grifo meu). 
Ora, levando em conta o que diz o autor, ao final de "O aparelho" acerca da enunciação escrita - "Esta se situa em dois planos: o que escreve se enuncia ao escrever e, no interior de sua escrita, ela faz os indivíduos se enunciarem" (Benveniste 1989: 90) -, poder-se-ia pensar que Benveniste restringiria a enunciação escrita à narrativa literária, na qual haveria autor e personagens, locutores, portanto. No entanto, não é assim que penso.

Sem dúvida, é verdade que Benveniste considera a enunciação escrita nesses termos, mas ele também a considera como podendo ser constituída de dois planos. Em cada um, o locutor enuncia a sua posição de locutor, a partir do que se torna o parâmetro de todas as condições necessárias da enunciação. É esse aspecto que, em minha opinião, interessa à abordagem da enunciação escrita: o fato de sempre haver uma variável - o locutor - "parametrizadora" de tudo o que constitui a enunciação. Nesse sentido, não há enunciação escrita sem locutor. Pode-se conceber até haver diferentes locutores em diferentes planos da enunciação escrita (caso da narrativa literária, por exemplo), mas não há enunciação escrita sem locutor. Com isso, desloca-se a problemática da autoria do texto para outra dimensão: a da presença do locutor. Assim, "enquanto realização individual", a enunciação é sempre referida àquele que enuncia, o locutor, independentemente do plano em que ele enuncia.

Por esse ato mesmo, introduz-se o outro. Vale repetir a passagem, deslocando-a, agora, para a problemática da enunciação escrita:

Mas imediatamente, desde que ele se declara locutor e assume a língua, ele implanta o outro diante de si, qualquer que seja o grau de presença que ele atribua a este outro. Toda enunciação é, explícita ou implicitamente, uma alocução, ela postula um alocutário (Benveniste 1989: 84).

Simetricamente ao que indaguei acima a respeito do locutor, cabe perguntar: Quem é o alocutário da enunciação escrita? O leitor do texto?

A resposta a essa questão exige reflexão acerca da noção de leitura mobilizada por uma teoria da enunciação. Creio que, em enunciação, é possível aceitar que o locutor, assim como produz a enunciação escrita, produz também a leitura da enunciação escrita. 
Com isso, quero dizer que se o leitor pode ser pensado como alocutário, isso somente é possível do ponto de vista do locutor, pois, do ponto de vista da leitura, o leitor é sempre um locutor. O leitor enuncia a leitura, a sua leitura. É isso que entendo pela ideia de locutor como "parâmetro", destacada acima. Se o locutor é sempre o "parâmetro" da enunciação, ao se considerar tanto a produção da escrita quanto a leitura da escrita, é do locutor que se trata sempre. Locutor e alocutário são, em suma, sempre colocutores.

\subsection{A situação em que o ato da enunciação escrita se realiza}

Em "O aparelho", lê-se:

A presença do locutor em sua enunciação faz com que cada instância de discurso constitua um centro de referência interno. Esta situação vai se manifestar por um jogo de formas específicas cuja função é de colocar o locutor em relação constante e necessária com sua enunciação (Benveniste 1989: 84, grifo meu).

Dessa passagem, é possível reter, de início a centralidade da noção de instância de discurso. Além disso, segundo Benveniste, "na enunciação, a língua se acha empregada para a expressão de uma certa relação com o mundo" (Benveniste 1989: 84). Quer dizer, de um lado, a situação diz respeito à necessidade de o locutor referir e de o alocutário correferir pelo discurso; de outro lado, essa construção da referência está na dependência da instância de discurso.

É importante notar que Benveniste fala em "uma certa relação com o mundo", isto é, uma relação que não é direta e que está na dependência da enunciação. Trata-se de ver como locutor e alocutário - constitutivos do ato enunciativo - referem e correferem via discurso, construindo um sentido singular acerca do que falam. Esse sentido é a referência e não o referente. A referência - cuja natureza é discursiva - é o sentido construído na interlocução. Enfim, "a referência é parte integrante da enunciação” (Benveniste 1989: 84).

Esse sentido construído na enunciação depende de um mecanismo específico, qual seja: o ato individual (a enunciação) introduz a instância de 
discurso (o conjunto das circunstâncias que inclui as coordenadas de tempo, espaço e pessoa) - e não mais o mundo - como centro de referência.

Admitido esse raciocínio, deveriam encontrar respostas as seguintes questões: Como se constrói a referência na enunciação escrita? Como se constroem as relações espaço-temporais na enunciação escrita (O aqui-agora)? Há uma situação de produção da enunciação escrita? Há uma situação de leitura da enunciação escrita?

Ou seja, em todas as perguntas está contida a ideia de que há formas que permitem ao locutor, na enunciação escrita, uma relação constante e necessária com a sua própria enunciação, e isso é específico da enunciação escrita.

\subsection{Os instrumentos de realização da enunciação escrita}

"O aparelho formal da enunciação", ao sugerir uma distinção entre índices específicos - constituídos pelas categorias de pessoa (eu/tu), tempo (agora) e espaço (aqui) - e procedimentos acessórios, permite entrever diferentes recursos que possibilitam ao locutor enunciar a sua posição de locutor.

Os pontos que merecem maior atenção aqui dizem respeito às particularidades dos índices específicos da enunciação escrita. Como se apresentam tempo, espaço e pessoa na enunciação escrita, considerados ato e situação? E os procedimentos assessórios? Como se apresentam na enunciação escrita?

Se por um lado, é óbvio que tanto índices específicos quanto procedimentos acessórios se apresentam, na enunciação escrita, a partir das restrições impostas pela língua - no caso, aqui, a língua portuguesa -, por outro lado, não se pode ignorar que, na enunciação escrita, há uma especificidade do que é da ordem do escrito, dessa materialidade, uma vez que nela estão implicadas figuras como autor e leitor e processos como produção e leitura. Mapear esses recursos e compreender sua forma de realização na enunciação escrita é, em si, o projeto cujas bases estão apenas sugeridas aqui. 


\section{Conclusão}

Enfim, é tempo de concluir. Minha intenção aqui foi apenas trazer para discussão alguns elementos que, acredito, podem contribuir para desenvolver uma pesquisa que, embora com base em Benveniste, vá além do que o linguista conseguiu formular, o que exige deslocamentos e novas formulações conceituais.

Em linhas gerais, pode-se considerar alguns pontos para encaminhar uma conclusão, mesmo que inicial.

As formulações que Benveniste faz sobre o primeiro elemento do quadro formal da enunciação, o ato, permitem um deslocamento - não explícito no texto "O aparelho" - para o estudo do ato da enunciação escrita, assim nomeada no final do artigo, qual seja: a dupla ${ }^{7}$ instância enunciativa - o que escreve se enuncia ao escrever e, no interior de sua escrita, ele faz os indivíduos se enunciarem - que é concomitantemente instaurada impõe descrever a enunciação escrita do ponto de vista dos locutores/interlocutores que se instauram nessa dupla cena, o que significa que uma teoria enunciativa da escrita implica necessariamente uma teoria da leitura.

A situação, por sua vez, sendo o outro elemento do quadro formal da enunciação, institui o conjunto das circunstâncias - coordenadas de tempo, espaço e pessoa - a partir do qual se constrói a referência.

E como se dá essa referência especificamente na situação da enunciação escrita acima? Nesse caso, não podemos esquecer que há uma situação de produção da enunciação escrita e uma situação de leitura da enunciação escrita. Ambas não coincidem em termos de coordenadas de espaço-tempo-pessoa. Em outras palavras, as circunstâncias de produção de uma enunciação escrita estão necessariamente em disjunção com as circunstância de leitura. Com isso, pode-se dizer que referência e correferência estão separadas pelas circunstâncias de tempo-espaçopessoa da produção e da leitura de uma enunciação escrita.

7. Quando dizemos que se trata de uma "dupla" instância, não estamos querendo, com isso, limitar o número de instâncias. Podem existir - e normalmente é o caso - mais de duas instâncias enunciativas em um texto. Com a ideia do duplo apenas queremos resguardar que se trata da instância de quem escreve e dos demais. 
Dos inúmeros desdobramentos de uma análise da situação da enunciação escrita, eu gostaria de destacar um parâmetro fundamental do qual emergem todos os desdobramentos possíveis: a disjunção da instância de discurso da leitura em relação à instância de produção, sendo, ambas, constitutivas da situação da enunciação escrita.

Finalmente, os instrumentos da enunciação escrita dizem respeito às marcas deixadas nos diferentes planos da enunciação - daquele que escreve e dos indivíduos que este faz se enunciar. Essas marcas caracteres formais - são, de um lado, aspectos pontuais marcados no texto (tais como os tempos verbais, indicadores de tempo, de pessoa e de espaço, os chamados índices de ostensão), e, de outro lado, todas as relações particulares de forma e sentido que se estabelecem em uma dada enunciação, os procedimentos acessórios da enunciação. Com relação à particularidade da enunciação escrita, esses instrumentos precisam ser observados levando em consideração a complexidade desse tipo de enunciação, que comporta, como ressaltado anteriormente, uma dupla cena enunciativa. Dessa forma, a escrita comporta tanto as marcas daquele que escreve quanto daqueles que o autor faz se enunciarem em seu texto.

A partir das sumárias reflexões apresentadas aqui, espero ter reunido argumentos que permitam repensar a escrita no quadro formal de realização da enunciação escrita. Creio, enfim, que, como Benveniste mesmo diria, "Amplas perspectivas se abrem para a análise das formas complexas do discurso, a partir do quadro formal esboçado aqui" (Benveniste 1989: 90).

Recebido em: 10/02/2017

Aprovado em: 10/04/2017

E-mail: valdirnf@yahoo.com.br

\section{Referências bibliográficas}

ARESI, Fábio. 2011. Os índices específicos e os procedimentos acessórios da enunciação. Revista Virtual de Estudos da Linguagem. 9/16.

Benveniste, E. 1988. Problemas de linguística geral I. Tradução de Maria da Glória Novak e Maria Luiza Neri. Campinas/SP: Pontes. 
. 1989. Problemas de linguística geral II. Tradução de Eduardo Guimarães [et al]. Campinas/SP: Pontes.

.2014. Últimas aulas no Collège de France 1968 e 1969. Tradução de Daniel Costa da Silva [et al]. São Paulo: Editora Unesp.

Flores, Valdir do Nascimento. 2013a. Introdução à teoria enunciativa de Benveniste. São Paulo: Parábola.

. 2013b. Sujeito da enunciação: singularidade que advém da sintaxe da enunciação. D.E.L.T.A. 29/1: 95-120. Disponível em: $<$ http://www.scielo.br/scielo.php?script=sci_arttext\&pid=S0102$44502013000100005 \& \operatorname{lng}=$ pt\&nrm=iso $>$. Acesso em $12 \mathrm{dez}$. 2016.

KNACK, C. 2012. Texto e enunciação: as modalidades falada e escrita como instâncias de investigação. Porto Alegre: Dissertação (Mestrado em Letras) - Instituto de Letras, Universidade Federal do Rio Grande do Sul.

Mello, V. H. D.; Schawabe, Cláudia R.; Stein, Jorama. 2015. O sabor do re-viver: o jogo entre índices específicos e procedimentos acessórios. Intersecções. 1/294-312.

SiLva, C. L. C. 2016a. Experiências de significação na linguagem e ensino de língua materna. Signo. 41: 20-28.

.2016b. A conversão da língua em discurso: enunciar para significar. Antares. 8: 15-28.

Toldo, Claudia \& Flores, Valdir do Nascimento. 2015. Esboço de uma abordagem enunciativa do texto. In: Toldo, Cláudia \& STURN, Luciane. Letramento: práticas de leitura e escrita Vol. 1. Campinas/ SP: Pontes. p. 37-49. 